it also has the advantage that it brings together for ready reference a series of articles dealing with one of the most important, and at the present time one of the most rapidly developing branches of medicine.

Pulmonary tuberculosis is the subject of seven of the nineteen articles in this volume, the particular aspects of the subject treated being early diagnosis, pulmonary tuberculosis in young adults, the heart in pulmonary tuberculosis, senile phthisis, the employment of simultaneous bilateral artificial pneumothorax and the care of arrested pulmonary tuberculosis. Thoracoplasty, pleurisy with effusion and spontaneous pneumothorax are other topics which come under review.

As an appendix there is supplied some, but in our opinion rather scanty, statistical information regarding the cases treated during the year at the hospital. In view of the wealth of clinical material which passes through this most important institution it seems a pity that it is not submitted to a more detailed analysis since we feel sure that in this way much important information would be obtained and rendered available for reference.

\section{THORACIC SURGERY.}

A revised and abridged edition of Sauerbruch's Die Chirurgie der Brustorgane.

By. Ferdinand Sauerbruch and Laurence O'Shaughnessy. Edward Arnold \& Co. London. 1937. Price 50\%- net.

One of the most important and far reaching developments of surgery in recent years is the surgery of the chest. Surgical intervention in the chest was made possible with the introduction of differential pressure anæsthesia in 1904. One of the pioneers in this branch of surgery is Ferdinand Sauerbruch who reviewed his extensive experience in his work-Die Chirurgie der Brustorgane. We welcome the appearance of this work in concise English form to which is added a résumé of other significant contributions to the subject during the last ten years.

The first sections of the book are occupied with an excellent account of the function of the lungs, general diagnosis, general technique of thoracic surgery, the control of an open pneumothorax, the technique of thoracotomy and post-operative treatment.
There follows an excellent detailed account of the surgery of the various parts of the chest.

With regard to certain details in the book we feel that the modern concept of diverticula of the cesophagus based on recent careful work could have been incorporated with advantage to the exclusion of the timehonoured classification of traction and pressure diverticula. We notice that the authors give but little attention to the use of irradiation therapy in the treatment of cancer of the csophagus. A notable advance in the treatment of this disease has been the development of a technique whereby the œsophageal growth is efficiently irradiated by high voltage $\mathrm{X}$-rays. The technique of œsophageal resection is considered in detail but we feel that more work is required in this field before resection of the œesophagus becomes a really practical proposition.

We welcome the excellent account of the surgical treatment of cardiac ischæmia which is given in the appendix. O'Shaughnessy is to be congratulated on the contribution which he has made to the surgery of the heart.

The book is produced well with many excellent illustrations. An excellent bibliography is available at the end. This work should be in the possession, not only of the physician and surgeon interested especially in diseases of the chest but also of the general surgeon and the general practitioner.

\section{HEART DISEASE AND PREGNANCY.}

By CRIGhton Bramwell, M.A., M.D., F.R.C.P., and EDITH A. Longson, M.B., Ch.B., D.P.H. With a foreword by Sir Ewen Maclean, M.D., F.R.C.P., LLD., D.Sc., etc. Pp. 206 : 57 illustrations. Humphrey Milford, Oxford University Press. London. 1938. Price $8 / 6$ net.

This short and very readable monograph is written for general practitioners.

The clinical manifestations of those types of heart disease which affect young women are well described and cover a large part of the text.

The conclusions with regard to treatment and prognosis are based on a full investigation of a series of 350 cases of organic heart disease, all of whom were observed 